\title{
Aspectos da divisão sexual do trabalho e o consumo alimentar fora do lar:
}

os impactos para o trabalho das mulheres

\section{Aspects of the sexual division of labor and food consumption away from home:}

impacts on women's work

Iriana Cadó ${ }^{1}$

Luciana de Oliveira Silva ${ }^{2}$

O objetivo da comunicação é associar a alimentação fora do lar à divisão sexual do trabalho, apresentando de que forma comer fora ou dentro de casa tem implicações para a mulher, a quem são atribuídas socialmente as tarefas de planejamento alimentar e preparo das refeições dentro da esfera domiciliar. Busca-se responder se uma maior socialização pública, isto é, a retirada da esfera privada da realização destas tarefas - que são generificadas - contribui para a diminuição do número de horas trabalhadas no âmbito privado, permitindo uma inserção mais igualitária das mulheres no trabalho produtivo.

O aumento das despesas das famílias com a alimentação fora do lar foi significante nos anos 2000 no Brasil. A média mensal de gastos para essa categoria de uma família passou de $24,1 \%$ em 2002 para 31,1\% em 2008. O hábito de comer fora de casa é uma tendência mundial que a população brasileira acompanhou nesse período. A expansão desse setor pode ser entendida por questões estruturais como a urbanização acelerada; como pela recente conjuntura econômica entre 20032014 caracterizada por um crescimento econômico junto com inclusão social, com bons indicadores do mercado de trabalho e do campo social. Esse período trouxe elementos para que o Brasil fosse pensado a partir de um projeto de desenvolvimento ancorado no consumo de massa. Assim, no regime de crescimento da demanda das famílias ocorreu um aumento da renda familiar que provocou incremento da demanda de serviços de alimentação.

Historicamente, a inserção das mulheres no mercado de trabalho é marcada pela divisão sexual do trabalho. Segundo Danièle Kergoat e Helena Hirata, as relações socioeconômicas se fundamentam na articulação das esferas da produção e da reprodução, tendo dois princípios elementares: separação e hierarquização. A divisão sexual do trabalho configura-se como um determinante da condição inferior da mulher no mercado de trabalho e o trabalho doméstico permanece principalmente sob a responsabilidade das mulheres. Segundo a Pesquisa Nacional por Amostra de Domicílios, o número de horas trabalhadas pelas mulheres na esfera doméstica manteve-se estável desde 2001. Enquanto as mulheres dedicam, em média, 21,3 horas semanais a afazeres e/ou cuidados, os homens dedicam 10,9 horas. Ademais, 95\% das mulheres era responsável por preparar ou servir alimentos, arrumar a mesa ou lavar louça contra 60\% dos homens em 2018.

A metodologia consiste em uma revisão bibliográfica sobre: i) trabalho reprodutivo e a inserção das mulheres no trabalho produtivo; ii) o consumo alimentar das famílias no contexto econômico dos anos 2000 e análise de dados da PNAD e da POF. Esta comunicação amplifica as 
dimensões de como o local da alimentação impacta o trabalho da mulher, tendo como hipótese que apesar das mudanças de hábitos de consumo alimentar no Brasil, não há uma amenização da divisão sexual do trabalho e há manutenção da carga de trabalho da mulher no âmbito doméstico que permeia sua inserção precária no mercado trabalho.

Palavras-chave: divisão sexual do trabalho; consumo alimentar; trabalho.

Keywords: sexual division of labor; food consumption; work.

1 Mestranda em Desenvolvimento Econômico pela Universidade Estadual de Campinas.

2 Mestranda em Desenvolvimento Econômico pela Universidade Estadual de Campinas. 